\title{
Erratum to: Development of redox-sensitive red fluorescent proteins for imaging redox dynamics in cellular compartments
}

\author{
Yichong Fan ${ }^{1}$ Hui-wang $\mathbf{A i}^{1,2}$
}

Received: 26 January 2016 / Accepted: 26 January 2016 / Published online: 12 February 2016

(C) Springer-Verlag Berlin Heidelberg 2016

\section{Erratum to: Anal Bioanal Chem}

DOI 10.1007/s00216-015-9280-3

The original version of this article unfortunately contained a mistake. The online abstract figure has an error. The correct version of the online abstract figure is given below and the original article was corrected.

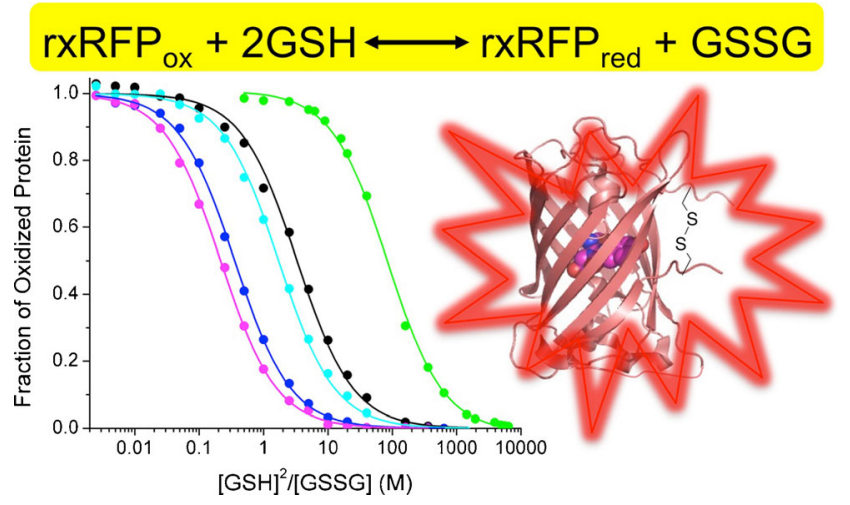

Published in the topical collection featuring Young Investigators in Analytical and Bioanalytical Science with guest editors S. Daunert, A. Baeumner, S. Deo, J. Ruiz Encinar, and L. Zhang.

The online version of the original article can be found at http://dx.doi.org/ $10.1007 / \mathrm{s} 00216-015-9280-3$.

Hui-wang Ai

huiwang.ai@ucr.edu

1 Environmental Toxicology Graduate Program, University of California Riverside, 501 Big Springs Road, Riverside, CA 92521, USA

2 Department of Chemistry, University of California Riverside, 501 Big Springs Road, Riverside, CA 92521, USA 